\title{
Low socioeconomic status and lung function
}

\author{
To the Editor:
}

The study by TAYLOR-ROBINSON et al. [1] is unique because of the large number of subjects with cystic fibrosis, the careful follow-up and detailed statistical analysis upon which the authors base their conclusions. This remarkable study was performed in a population with reduced life expectancy. Evaluating the impact of socioeconomic status (SES) on lung function over many decades is particularly daunting in subjects with respiratory disease. Ever since the pioneering work of VILLERMÉ [2, 3], the founding father of social epidemiology, numerous studies have documented an association of SES with growth as well as with mortality in adulthood. It is also generally accepted that adverse conditions during childhood lead to stunted growth. For example, in a study of Indian children [4], stature was $4 \%$ smaller in the group with the lowest, compared with the highest, SES, and associated with up to $16.7 \%$ differences in forced expiratory volume in $1 \mathrm{~s}(\mathrm{FEV} 1)$ and forced vital capacity (FVC); adjusting for age and differences in height did not explain these differences. It is therefore attractive to conclude that the lower ("worse", "poorer" or "compromised") FEV1 and FVC represent damage associated with poor SES. Whereas this may well be the case, association is no proof of causality. The conclusion hinges entirely on the notion that stature is a good proxy for the dimensions of the chest cavity. However, poor SES or nutritional and health problems (lumped together as SES for short) during early childhood are associated with smaller leg length relative to the height of the upper body segment [5], which biases prediction equations of lung function based on height. There is no evidence that growth stunting due to poor SES is limited to height, so it is logical to assume that chest dimensions will also be affected. If poor SES leads to a $1 \%, 2 \%$ or $3 \%$ lower width, depth and height of the thoracic cage, this leads to a 3\%, $6 \%$ and $9 \%$ lower volume of the chest cavity, respectively. Taking into account measurement error and individual variability, it will be difficult to assess such small differences, but they cannot be discarded and might (in part) explain the observed difference in growth of FEV1. Measurements of chest circumference in a large number of subjects might throw some light on the role of differences in body frame.

It is intuitively attractive to relate causally a lower SES level in childhood to irreparable lung damage, and to a potentially larger decline in lung function, and higher respiratory morbidity and mortality in adulthood. Extrapolating from childhood over many decades of adult life is fraught with danger. Even in affluent countries, upward mobility from a low to a higher SES is limited [6]. Therefore, it is a bold step to disregard the potential role of poor SES over decades of adult life. Finally, it is of interest to know whether in individuals with the lowest SES, the vital capacity and FEV1 were proportionally smaller; no difference in the $\mathrm{FEV}$ //FVC ratio would argue against the development of an obstructive ventilatory defect and point to restricted chest growth.

@ERSpublications

It is bold to disregard the potential role of poor socioeconomic status in lung function over decades of adult life http://ow.ly/DW6kn

Philip H. Quanjer ${ }^{1,2}$

${ }^{1}$ Dept of Pulmonary Diseases, Erasmus University Medical Centre, Rotterdam, The Netherlands. ${ }^{2}$ Dept of Paediatrics, Division of Respiratory Medicine, Erasmus University Medical Centre - Sophia Children's Hospital, Rotterdam, The Netherlands.

Correspondence: E-mail: pquanjer@gmail.com

Received: Oct 172014 | Accepted: Oct 252014

Conflict of interest: None declared.

References

1 Taylor-Robinson DC, Thielen K, Pressler T, et al. Low socioeconomic status is associated with worse lung function in the Danish cystic fibrosis population. Eur Respir J 2014; 44: 1363-1366.

2 Villermé L-R. Mémoire sur la taille de l'homme en France [Report on the height of men in France]. Annales d'Hygiène Publique et de Médecine 1829; 1: 351-399.

3 Villermé L-R. Mémoire sur la mortalité en France dans la classe aisée et dans la classe indigente [Report on mortality in France in the affluent class and the indigent class]. Mémoires de l'Académie Royale de Médecine 1828; 51-98.

4 Raju PS, Prasad KV, Ramana YV, et al. Influence of socioeconomic status on lung function and prediction equations in Indian children. Pediatr Pulmonol 2005; 39: 528-536. 
5 Wadsworth ME, Hardy RJ, Paul AA, et al. Leg and trunk length at 43 years in relation to childhood health, diet and family circumstances; evidence from the 1946 national birth cohort. Int J Epidemiol 2002; 31: 383-390.

6 Corak M. Do poor children become poor adults? Lessons from a cross country comparison of generational earnings mobility. IZA Discussion Paper No. 1993. http://ftp.iza.org/dp1993.pdf Date last updated: March 2006.

Eur Respir J 2015; 45: 856-857 | DOI: 10.1183/09031936.00178414 | Copyright (CERS 2015

From the authors:

We thank P.H. Quanjer for his comments regarding our paper, in which we apply a novel modelling approach to lung function data from the unique Danish cystic fibrosis registry and show that low socioeconomic status (SES), as measured by parental education level, is associated with an increased rate of decline of \% predicted forced expiratory volume in $1 \mathrm{~s}$ in the Danish cystic fibrosis population [1]. We agree that it is important to develop a better understanding of the pathways to social inequalities in cystic fibrosis outcomes.

P.H. Quanjer points out that chest circumference may be an important mediator of the association between SES at birth and later lung function. Malnutrition and poor growth are major concerns in children with cystic fibrosis and optimising nutritional status is clearly important for subsequent lung health. Our analyses have shown social gradients in growth outcomes in children with cystic fibrosis in the UK, evident from around the time of diagnosis [2]. These findings point to important effects of SES in utero or in the initial period prior to diagnosis. Both are plausible, but a limitation of studies thus far has been a lack of data on social gradients in birth weight, which would complete the picture. Further data on SES gradients in birth weight in cystic fibrosis would clarify the extent to which the early growth differentials are simply a reflection of the broader SES effects on birth weight in the general population.

On a related point, height has been independently related to survival in people with cystic fibrosis and it has been suggested that this may be mediated through greater lung capacity in taller people [3]. Furthermore, FOGARTY and co-workers $[4,5]$ have suggested that measures of body habitus may partially explain the male survival advantage in cystic fibrosis. In the UK, SES has an important effect on height from the outset in children with cystic fibrosis and this difference tracks through to adulthood [2]. Further longitudinal analyses are required to understand how inequalities in birth length, and the factors that influence it, may influence chest capacity and lung function in adulthood, and ultimately survival, in cystic fibrosis.

P.H. Quanjer also points to the complex interaction between measures of SES and health over the life-course. The Diderichsen model of pathways to health inequalities has informed our analyses in cystic fibrosis $[6,7]$. A key feature of the Diderichsen model is that it incorporates both social causation and social selection mechanisms within a common framework, across the life-course. We encourage further studies that use this approach, in order to better unpick the complex causal chains that link social inequalities and health.

(7) @ERpublications

Studies should use the Diderichsen approach to unpick the causal chains that link social inequalities and health http://ow.ly/H406C

David C. Taylor-Robinson ${ }^{1}$, Karsten Thielen ${ }^{2}$, Tania Pressler ${ }^{3}$, Hanne V. Olesen ${ }^{4}$ and Peter J. Diggle ${ }^{5}$

${ }^{1}$ Dept of Public Health and Policy, University of Liverpool, Liverpool, UK. ${ }^{2}$ Dept of Social Medicine, University of Copenhagen, Copenhagen, Denmark. ${ }^{3}$ Cystic Fibrosis Center, Rigshospitalet, Copenhagen, Denmark. ${ }^{4}$ Pediatric Dept A, Cystic Fibrosis Center, Aarhus University Hospital, Aarhus, Denmark. ${ }^{5}$ Institute of Infection and Global Health, University of Liverpool, Liverpool, UK.

David Taylor-Robinson, Dept of Public Health and Policy, Whelan Building, University of Liverpool, Liverpool, L69 3GB, UK. E-mail: dctr@liv.ac.uk

Received: Dec 182014 | Accepted: Dec 182014

Support statement: This work was supported by an MRC Population Health Scientist Fellowship to D.C. Taylor-Robinson (grant G0802448). The funders had no role in study design, data collection and analysis, decision to publish, or preparation of the manuscript. Funding information for this article has been deposited with FundRef.

Conflict of interest: Disclosures can be found alongside the online version of this article at erj.ersjournals.com

\section{References}

1 Taylor-Robinson DC, Thielen K, Pressler T, et al. Low socioeconomic status is associated with worse lung function in the Danish cystic fibrosis population. Eur Respir J 2014; 44: 1363-1366. 